\title{
Risk analysis of wastewater reuse in agriculture
}

Jacques Ganoulis*

\begin{abstract}
Two of the main concerns for wastewater reuse in agricultural irrigation are environmental and human security. Different research studies and practices have been developed recently in order to quantify the risk of possible environmental contamination of surface and groundwater resources as well as the risk to public health from enteric viruses. Other, far from negligible, related issues are largely of a socio-economic and technical character. For example, the social acceptance, especially by farmers, of wastewater reclamation and reuse in agriculture is influenced by specific local cultural, religious and socio-economic conditions. Economic and technical factors should also be taken into consideration, such as the water and wastewater treatment costs, the cost of maintenance, the employment of rural labour, the structure of irrigation networks and crop patterns. In this paper, the concept of sustainability in wastewater reclamation and reuse is formulated by using a general risk analysis framework and by taking into account all the above factors. The paper suggests a methodology for sustainable wastewater reuse in agriculture by considering not only technical and economic factors, but also environmental and social risks. Alternative strategies based on different treatment and irrigation technologies are evaluated using the multicriteria decision analysis technique. The methodology is illustrated in a case study of wastewater reclamation and agricultural reuse in the city of Thessaloniki, Macedonia, Greece.
\end{abstract}

Keywords: Wastewater reclamation, Reuse, Irrigation, Risk analysis, Multicriteria decision making

\section{Background}

In wastewater reclamation and reuse, the advanced treatment of municipal wastewater has been largely accepted as sufficient in order to satisfy public health and environmental concerns. However, even after tertiary wastewater treatment, there is still a risk from enteric virus, toxic contamination and pollution of the environment. The decision on whether to replace the conventional or other non-conventional water sources for the purposes of agricultural irrigation with reclaimed wastewater depends primarily on risks to public health that must be reduced to an acceptable level, and secondarily on environmental risks. For an acceptable solution both these should be weighed against economic benefits. To evaluate criteria and standards for wastewater reclamation and reuse, risk analysis and MCDA are very useful tools (Ganoulis 2003; 2009).

In the past, wastewater was processed to make it reusable for the purposes of:

Correspondence: iganouli@civil.auth.gr

UNESCO Chair for Sustainable Water, Department of Civil Engineering, Aristotle University of Thessaloniki, Thessaloniki 54124, Greece
- Wastewater treatment

- Protection of surface and groundwater resources

- Agricultural irrigation.

Although advanced wastewater treatment was tested in some Mediterranean countries and in the state of California, USA (Pettygrove and Asano (eds.) 1985), in most cases reclaimed wastewater is led to the sea and not used for irrigation. Also there is no systematic assessment of the risks involved in wastewater reuse. In the Mediterranean area there has been significant progress in this field and many applications have been tested, especially in countries such as Israel, Tunisia and Cyprus, where several methods for irrigation have been developed after tertiary treatment of wastewater coming from small units, like hotels and tourist residences (Papadopoulos 1989).

There are well-known historical examples of wastewater reclamation and reuse in big industrial cities in northern Europe (Berlin, 1836; London, 1845; Paris, 1875). However, it is in regions with a semi-arid climate and long-lasting droughts (Mediterranean, California) where such practices have been and should be developed

\section{空}

(C) 2012 Ganoulis; licensee Springer. This is an Open Access article distributed under the terms of the Creative Commons Attribution License (http://creativecommons.org/licenses/by/2.0), which permits unrestricted use, distribution, and reproduction in any medium, provided the original work is properly cited. 
(Angelakis 1993). Two literature reviews refer to technical developments and applications of wastewater reuse in the Mediterranean and in the state of California, USA (Pettygrove and Asano 1985).

A distinction should be made between the following:

- Indirect reuse, in which wastewater is first discharged to a receiving natural water system (aquifer, river) and then water is withdrawn downstream. Municipal wastewaters can be reclaimed and reused indirectly.

- Direct reuse, were the effluent is treated and reused immediately after reclamation. This is mostly the case for industrial wastewaters captured and reused in closed loops in industrial processes, such as pulp and paper industries.

In this paper we are interested in recycling municipal wastewaters for agricultural reuse in the Mediterranean socio-economic context. Significant progress has been made in this area and many applications have been tested, especially in countries such as Israel, Tunisia and Cyprus. Different methods for municipal wastewater reuse have already been developed in these countries. In Israel, 98\% of wastewater is treated, mostly by using ponds; the water is then used for irrigation (Sne 1990). In Tunisia, wastewater is treated by using active sludge and ponds (Saied and Koundi 1990). In Cyprus, several methods for irrigation have been developed after tertiary treatment of wastewater coming mostly from small units, like hotels and tourist residences (Papadopoulos 1989).

Although advanced wastewater treatment was tested in some Mediterranean countries, in most cases reclaimed wastewater is led to the sea and not used for irrigation. Also there is no systematic assessment of the risk involved in wastewater reuse. Taking the decision to reuse water for irrigation is complicated and problematic, as technological alternatives and local social and cultural conditions have to be taken into consideration. The water characteristics of importance in agricultural or landscape irrigation are specific chemical elements and bacteriological concentrations that affect plant growth and may threaten public health. These characteristics are not often measured or controlled by wastewater treatment agencies. Consequently, when obtaining data to evaluate or plan wastewater reuse and irrigation systems, it is necessary to assess the risk to public health. The problem will be formulated in terms of alternatives, economic benefits, environmental and other criteria in order to manage the different risks involved.

\section{Risk quantification \\ Definition of risk}

Risk and reliability have different meanings and are applied differently in various disciplines such as engineering, statistics, economics, medicine and social sciences. The situation is sometimes confusing because terminology and notions are transferred from one discipline to another without modification or adjustment. This confusion is further amplified as scientists may have different perceptions about risks and use different tools to analyse them.

Environmental risk is different from economic, social or health risks. It may refer to a pollutant concentration exceeding given regulations. Environmental risk analysis is based on the quantification of various uncertainties that may occur in the evolution of physical processes. The use of modelling techniques to quantify such uncertainties is an essential part of environmental risk analysis. Furthermore, because engineering projects are based on predictions of how processes might develop under uncertainty in the future, probabilistic approaches are more appropriate than deterministic methods for this purpose. Probabilities, and more recently the fuzzy set theory (Ganoulis 2009), are suitable tools for quantifying uncertainties, which may induce a risk of pollution and threats to human health.

The maximum concentration of a specific pollutant $\mathrm{Cm}$ may be chosen to indicate the adverse effects produced in the water environment. Depending on the specific use of water, e.g., irrigation, recreation, etc., a maximum allowable pollutant concentration, $\mathrm{C}_{0}$, is specified by the environmental quality standards. This concentration should be considered as the resistance $\mathrm{r}$ or the capacity of the environment to sustain pollution. A critical condition producing adverse effects and risk of pollution occurs when the maximum pollutant concentration $\mathrm{Cm}$ or the load 1 exceeds the receiving capacity of the system, i.e. when $\mathrm{Cm}>\mathrm{C}_{0}$. Otherwise the system is safe, as far as pollution is concerned. So we have:

$$
\begin{aligned}
& \text { pollution : } \mathrm{Cm}>\mathrm{C}_{0} \\
& \text { safety : } \mathrm{C}_{\mathrm{m}} \leq \mathrm{C}_{0}
\end{aligned}
$$

In a typical problem of failure under conditions of uncertainty, we usually face three main questions, which may be addressed in three successive steps (Ganoulis 2009):

Step 1 When does pollution occur?

Step 2 How often is pollution expected?

Step 3 What are the likely consequences?

The two first steps form part of the uncertainty analysis of the system. The answer to question 1 is given by the formulation of the critical condition in Equation (1), i.e. when the load $l$ exceeds the resistance $r$. To provide a satisfactory answer to question 2 we may consider the variables of the problem such as the load $l$ and resistance $r$, as non-deterministic. 
Uncertainties in wastewater reuse

A distinction should be made between

aleatory or natural uncertainties or randomness and, epistemic or man-induced or technological uncertainties.

\section{Aleatory uncertainties or randomness}

It is postulated that natural uncertainties are inherent to the specific process and they cannot be reduced by use of an improved method or more sophisticated model. Uncertainties due to natural randomness or aleatory uncertainties may be taken into account by using the stochastic or fuzzy methodologies, which enable us to quantify uncertainties.

\section{Epistemic or man-Induced uncertainties}

Man-induced uncertainties are of different kinds: (a) data uncertainties, due to sampling methods (statistical characteristics), measurement errors and methods of analysing the data (b) modelling uncertainties, due to the inadequate mathematical models in use and to errors in parameter estimation, and (c) operational uncertainties, which are related generally to the construction, maintenance and operation of engineering works. Contrary to natural randomness, man-induced uncertainties may be reduced by collecting more information or by improving the mathematical model.

\section{Risk management}

Management of water resources involves addressing not only technical issues but also many social factors, institutions and administrative procedures. The main objective of the effective management of water resources in urban environment is to satisfy the demand, given the

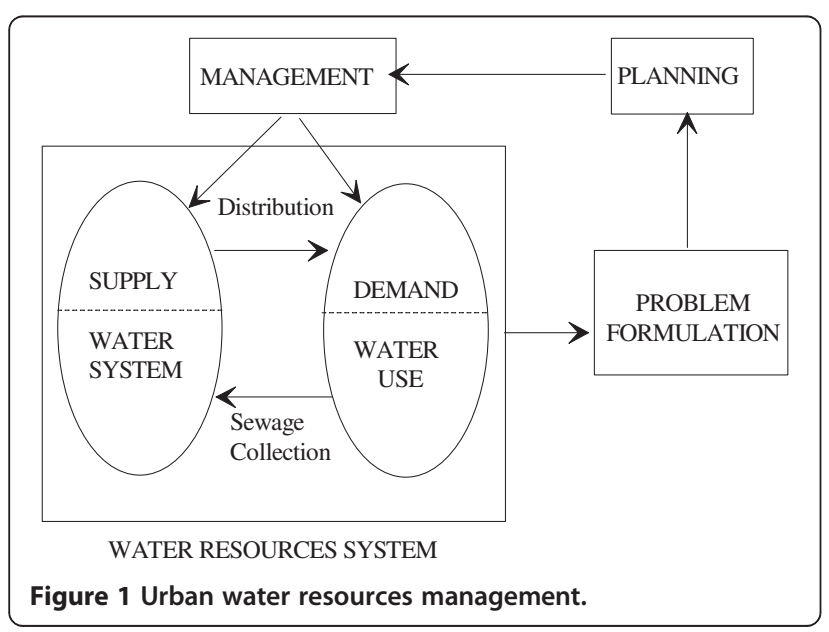

possibilities and limitations of water supply (Figure 1). This balance between supply and demand should take into consideration both water quantity and quality aspects and the protection of the environment.

As seen in Figure 2, the process leads to problem formulation, planning and management. The latter involves taking measures and regulating both water demand and supply. The various steps involved in the management of wastewater reuse, from problem formulation to decision-making, are described schematically in Figure 2. Various methodologies may be used (Ganoulis 2009) to identify and quantify risks, including the following:

- Statistical analysis of data

- Probabilistic modelling

- Fuzzy set approaches.

Quantification of risk as a function of technological methods, climatic factors, physical conditions and socioeconomic parameters is essential for the management of risk. As shown in Figure 3, application of engineering risk analysis consists of two main phases:

(1) Assessment of risk, and

(2) Risk management.

The assessment of risk is mainly based on modelling of the physical system, including forecasting of its

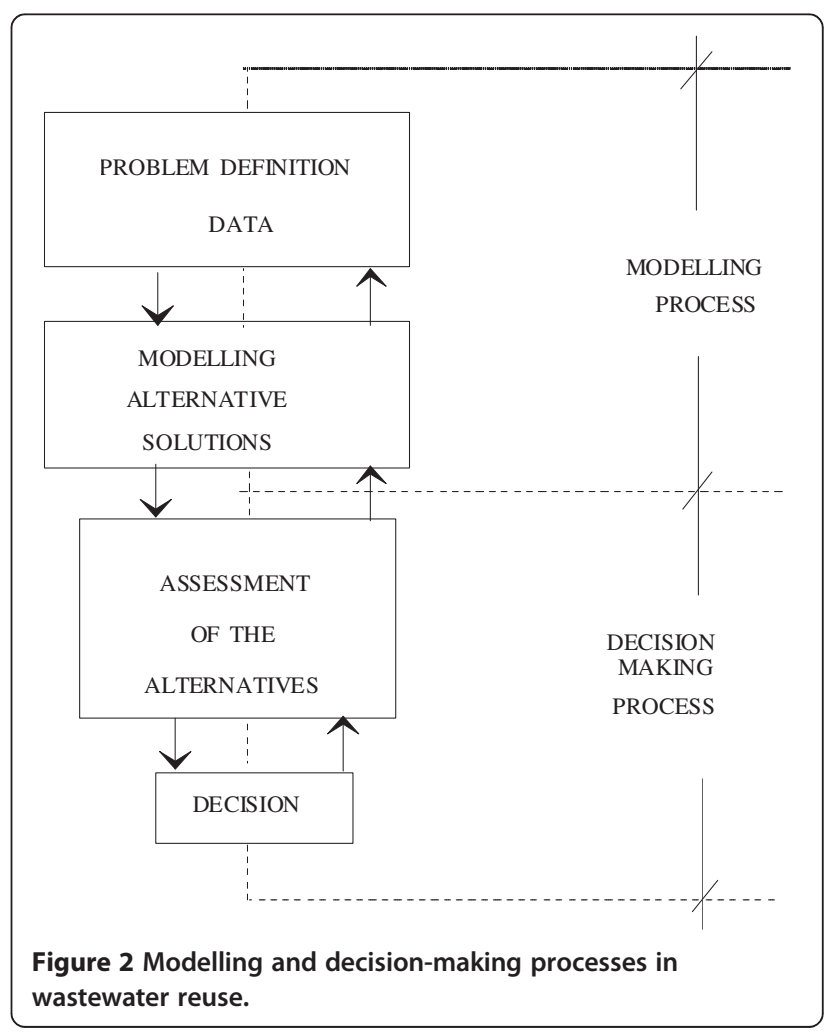




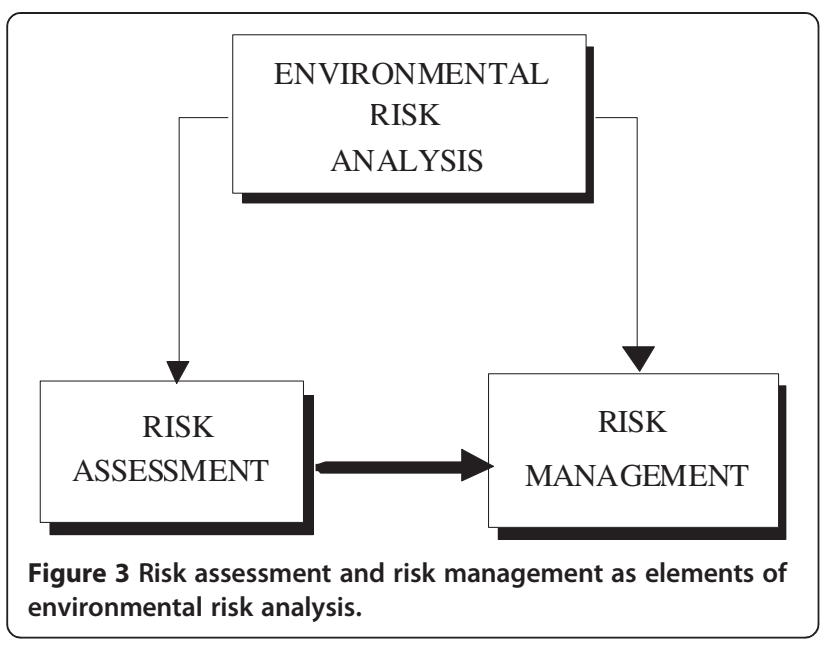

evolution under risk. Although the main objective of risk analysis is the management of the system, this is not possible if risk has not been quantified.

The risk assessment process involves the following steps:

Step 1 Risk or hazard identification

Step 2 Assessment of loads and resistance

Step 3 Uncertainty analysis

Step 4 Risk quantification

When it is possible to assess the risk under a given set of assumptions, then the process of risk management may begin.

The various steps that should be followed for risk management, are as follows:

Step 1 Identification of alternatives and associated risks

Step 2 Assessment of costs in various risk levels

Step 3 Technical feasibility of alternative solutions

Step 4 Selection of acceptable options according to the public perception of risk

Step 5 Implementation of the optimal choice

Due to the aspects involving human and social issues, risk management is both the most important and most difficult part of the whole process to develop. From an engineering point of view, theories and algorithms of optimisation under uncertainty, multi-criterion optimisation and decision making under risk are useful tools.

\section{Wastewater reuse}

For the management of risk related to wastewater reuse, 4 steps may be distinguished:

(1) Collection of existing data Data concerning not only wastewater reuse and the behaviour of major water pollutants but also reflecting the physical and socio-economic environment should be collected (topography, land use, river discharges, aquifer properties, human activities, agriculture, industries and urbanism).

(2) Data organisation

Data collected and information available may be processed and structured using a GIS. Groups of interrelated data will be formed in order to examine cause and effect relationships.

(3) Risk assessment

Various methods are used, such as

Statistical analysis of data

Probabilistic modelling, and

The fuzzy arithmetic approach.

These methodologies will allow the health risk to be evaluated for different exposure scenarios. Risk management

Expected benefits and costs will be expressed as a function of risk. The incremental benefits will be evaluated in terms of the risk, considering

\section{Alternative actions \\ Different states of nature and \\ Preferences or criteria.}

These problems should be considered while taking into account various technologies and different irrigation systems and also the local socio-economic conditions. In fact, wastewater reuse involves alternative technologies for sewage treatment (biological oxidation, nitrificationdenitrification, use of lagoons and aquifer recharge), different states of nature (climatic conditions, type of soils, irrigated crops, irrigation systems, socio-economic environments) and various preferences or criteria (economic, environmental, aesthetics, etc.).

The objectives of a related research project may be classified in two groups. Those of the first group concern mainly the technical and socio-economic aspects of wastewater reuse including:

- Developing a Decision Support System (DSS,) which may help local authorities to choose between alternatives of wastewater reuse, decide quickly about the risk and feasibility of a proposal and better adapt the solution to local conditions.

- Using the risk assessment and management framework in order to minimise risks to public health from wastewater reuse. Different scenarios should be developed to quantify public health risks due to wastewater reclamation and reuse. Different 
exposure assessments should be evaluated including groundwater recharge, food crop irrigation, landscape irrigation and recreational impoundment.

The second group of objectives deals with the applicability and diffusion of the results among potential users. Such objectives are as follows:

- Identification of potential users from public and private sectors

- Organisation of regular contact and exchange between users and research institutions

- Follow up of the evolution of research and evaluation of its adequacy to solve practical problems

- Creation of a network of regional operational institutions, in order to improve the distribution of results of wastewater reuse within the professional field.

\section{Example of application}

In environmental engineering the treatment and disposal of sewage is subject not only to the minimisation of environmental impacts, but also to the minimisation of costs, and the minimisation of adverse reaction from environmentalists and possibly other social groups. These objectives are usually conflicting. Improvement of one is obtained with the deterioration of another. Moreover, the objectives may be of varying degrees of importance. In the case of a Wastewater Treatment Plant (WTP), even if we restrict ourselves only to economic objectives, these could be in conflict, whether or not they are defined by the owner or operator of the regulatory agency.

This example of application should be treated as a decision-making problem under uncertainty or imprecision. We can evaluate the outcome, but we are not able to express the probabilities of occurrence objectively and quantitatively. Imprecision may also exist in the choice or evaluation of criteria, or in the evaluation of the outcome according to the potential user.

The set of criteria may contain quantified criteria and non-quantified criteria. For example, costs, technical characteristics and efficiencies may be measured in terms of money or other quantitative measures. Nonquantitative criteria are related to aesthetics, human comfort or environmental values. The following example refers to the Wastewater Treatment Plant in Thessaloniki, Greece.

The city of Thessaloniki disposes part of its total sewage untreated into the sea. An existing WTP could function with:

$$
\begin{aligned}
& \text { primary treatment and/or } \\
& \text { secondary treatment } \\
& + \text { chlorination } \\
& + \text { nitrification/denitrification. }
\end{aligned}
$$

In a multi-objective decision-making process, we may consider the Decision Matrix (Table 1), the Criteria and the Meaning of the Criteria Values (Table 2) as inputs, and the Pay-off Matrix (Table 3) and the Compromise Solution (Figure 4) as outputs.

The different disposal sites represent the States of $\mathrm{Na}$ ture, in the first line of the Decision Matrix (Table 1). The disposal site could be in the bay of Thessaloniki as it is now (site A), in the Axios River (site B), in the sea with an underwater pipe-line (site $C$ ), or in the fields for food crop or non-food crop irrigation (site D). These different possibilities form the possible "Alternatives" (Table 1). These are environmental conditions in which the actions should operate, and called "nature". In a decision-making situation, nature can include technical, physical, political, social and economic considerations. The members of the set are mutually exclusive and exhaustive.

In the first column of the Decision Matrix, we list the

\begin{tabular}{|c|c|c|c|c|c|}
\hline \multirow[t]{2}{*}{ Actions } & \multicolumn{5}{|c|}{ Disposal Sites (States of Nature) } \\
\hline & Thessaloniki Bay & AxiosRiver & OpenSea & Food-croplrrigation & No Food-croplrrigation \\
\hline & Site A & Site B & Site C & Site D & Site D \\
\hline No Treatment & No & No & $\mathrm{A} 1$ & No & No \\
\hline Primary Treatment & No & No & $\mathrm{A} 2$ & $\underline{\mathrm{A}}^{\mathrm{a}}$ & $\underline{\mathrm{A}} 4^{\mathrm{a}}$ \\
\hline $\begin{array}{l}\text { Secondary Treatment } \\
\text { and Chlorination }\end{array}$ & A5 & A6 & A7 & $\underline{\mathrm{A}}^{\mathrm{a}}$ & $\underline{\mathrm{A}}^{\mathrm{a}}$ \\
\hline $\begin{array}{l}\text { Secondary Treatment (+chlorine) } \\
\text { and Nitrification-Denitrification }\end{array}$ & A10 & A11 & $\mathrm{A} 12$ & ${\underline{\mathrm{A} 13^{\mathrm{a}}}}^{\mathrm{a}}$ & ${\underline{\mathrm{A} 14^{\mathrm{a}}}}$ \\
\hline
\end{tabular}
Alternative Actions. These are alternative design solutions that engineers can select as potential solutions to

Table 1 decision matrix for thessaloniki wtp

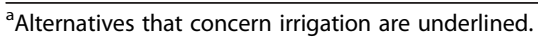


Table 2 Meaning of the criteria values

\begin{tabular}{|c|c|c|c|c|c|}
\hline Criteria & Meaning of criteria values & & & & \\
\hline $\mathrm{C} 1$ & $A=$ cheap & $\mathrm{B}=$ not expensive & $\mathrm{C}=$ fair price & $\mathrm{D}=$ expensive & \\
\hline $\mathrm{C} 2$ & $A=$ cheap & $B=$ not expensive & $C=$ fair price & $\mathrm{D}=$ expensive & \\
\hline $\mathrm{C} 3$ & $A=$ cheap & $\mathrm{B}=$ not expensive & $C=$ fair price & $\mathrm{D}=$ expensive & \\
\hline C4 & $\mathrm{A}=$ excellent & $\begin{array}{l}\mathrm{B}=\mathrm{a} \text { little nuisance from } \\
\text { time to time }\end{array}$ & $\mathrm{C}=\mathrm{a}$ little nuisance & $\mathrm{D}=$ frequent nuisance & \\
\hline C5 & $\begin{array}{l}A=a \text { lot of fish and diversity } \\
\text { of species }\end{array}$ & $B=a$ lot of fish & $C=$ few fish & $D=$ fishing is forbidden & $\mathrm{E}=$ dead sea \\
\hline C6 & $\mathrm{A}=$ excellent & $\mathrm{B}=$ good for swimming & $\mathrm{C}=$ possible to swim off season & $\mathrm{D}=$ dangerous & \\
\hline$C 7^{\mathrm{a}}$ & $\mathrm{A}=<14 / 100 \mathrm{ml}$ & $B=<100 / 100 \mathrm{ml}$ & $C=\leq 1000 / 100 \mathrm{ml}$ & $\mathrm{D}=\leq 100000 / 100 \mathrm{ml}$ & $E=>100000 / 100 \mathrm{ml}$ \\
\hline $\mathrm{C} 8$ & $\mathrm{~A}=$ promotes growth & $\mathrm{B}=$ no change & $\mathrm{C}=$ toxic or overgrowth & & \\
\hline
\end{tabular}

Based on WHO (2011).

the problem. Because of the various limitations, such as technological or modelling constraints, it is not possible to find all the possible alternative actions. This means that the set of the actions is not exhaustive. However the members of the set are mutually exclusive. In this case the actions are the different degrees of sewage treatment.

For every combination between an Action and a State of Nature, we obtain an Outcome in Table 1, from A1 to A14.

Each management alternative is associated with economic, ecological and social impacts, expressed by means of some Basic Indicators (BI) or Criteria. The basic indicators are grouped (Figure 5) into smaller, more general groups, called second-level indicators or objectives. This grouping continues until only two indicators, such as economy and environmental risk, remain.

By defining the objectives of the problem, it is possible to choose the Criteria or Basic Indicators (BI), that may be an economic, social, or public health risk (Figure 5). After the indicators have been grouped into such a structure (Figure 5), weights are assigned to the indicators representing their relative importance to the decision maker. For example a moderate risk to humans may be considered more important than a more severe risk to a non-endangered species of fish.

The criteria may be quantified or non-quantified. The capital, land and function costs may be measured in money. Nevertheless the characterisation of $\mathrm{A}=$ cheap, or $\mathrm{B}=$ not expensive, etc. may be subjective, according to the user or the decision maker. Recreation (C4), is a non-quantified criterion, that we may measure according to the odour nuisance to people.

The criteria C7 and C8 refer to the European Environmental quality standards. $\mathrm{C} 7$ is measured by the presence of faecal coliforms at the exit of the WTP and the limits correspond to the acceptable limits for food crop irrigation and no-food crop irrigation. Measurement in situ may generate other uncertainties, related to climate conditions, (summer, winter, river flow, etc.).

The difficult part is to determine the numerical values A, B, C, etc. These values may be the results of an environmental model (pollutant concentrations), an economic investigation, a poll, or constraints according to environmental standards for each alternative solution. On the other hand, the weights may vary according to the potential user or the decision maker. We may limit this variation using sensitivity analysis. The units of basic

Table 3 Pay-off matrix

\begin{tabular}{|c|c|c|c|c|c|c|c|c|c|c|c|c|c|c|c|c|}
\hline & CRITERIA & w & A & A & $\underline{A}$ & $\underline{A}$ & A & $A$ & A & $\underline{A}$ & $\underline{A}$ & A & A & A & $\underline{A}$ & $\underline{A}$ \\
\hline & & & 1 & 2 & $3^{a}$ & $4^{a}$ & 5 & 6 & 7 & $8^{a}$ & $9^{a}$ & 10 & 11 & 12 & $13^{a}$ & $14^{\mathrm{a}}$ \\
\hline & C1 capital cost & $w_{1}$ & A & $B$ & B & $B$ & C & $C$ & C & $C$ & $C$ & C & D & $\mathrm{D}$ & $\mathrm{D}$ & $\mathrm{D}$ \\
\hline \multirow[t]{3}{*}{$30 \%$} & C2 land cost & $w_{2}$ & A & $\mathrm{B}$ & B & B & B & $\mathrm{B}$ & B & $\mathrm{B}$ & $\mathrm{B}$ & C & C & C & C & C \\
\hline & C3 function & $w_{3}$ & B & B & B & B & B & C & C & $C$ & $C$ & C & C & D & $\mathrm{D}$ & D \\
\hline & C4 recreation & $W_{4}$ & $\mathrm{D}$ & $B$ & B & B & B & $B$ & B & $\mathrm{B}$ & $\mathrm{B}$ & A & A & A & A & A \\
\hline \multirow[t]{2}{*}{$20 \%$} & C5 fishing & $W_{5}$ & C & $B$ & A & A & B & B & B & A & A & A & A & A & A & A \\
\hline & C6 swimming & $w_{6}$ & B & B & A & A & C & C & A & A & A & A & A & A & A & A \\
\hline \multirow[t]{2}{*}{$50 \%$} & C7 human health (coliform.) & $w_{7}$ & $\mathrm{E}$ & $E$ & $\mathrm{E}$ & $\mathrm{E}$ & A & A & A & A & A & A & A & A & A & A \\
\hline & C8 plants' response & $w_{8}$ & B & $\mathrm{B}$ & C & C & B & B & B & A & A & B & B & B & B & B \\
\hline
\end{tabular}

${ }^{a}$ Alternatives that concern irrigation. 


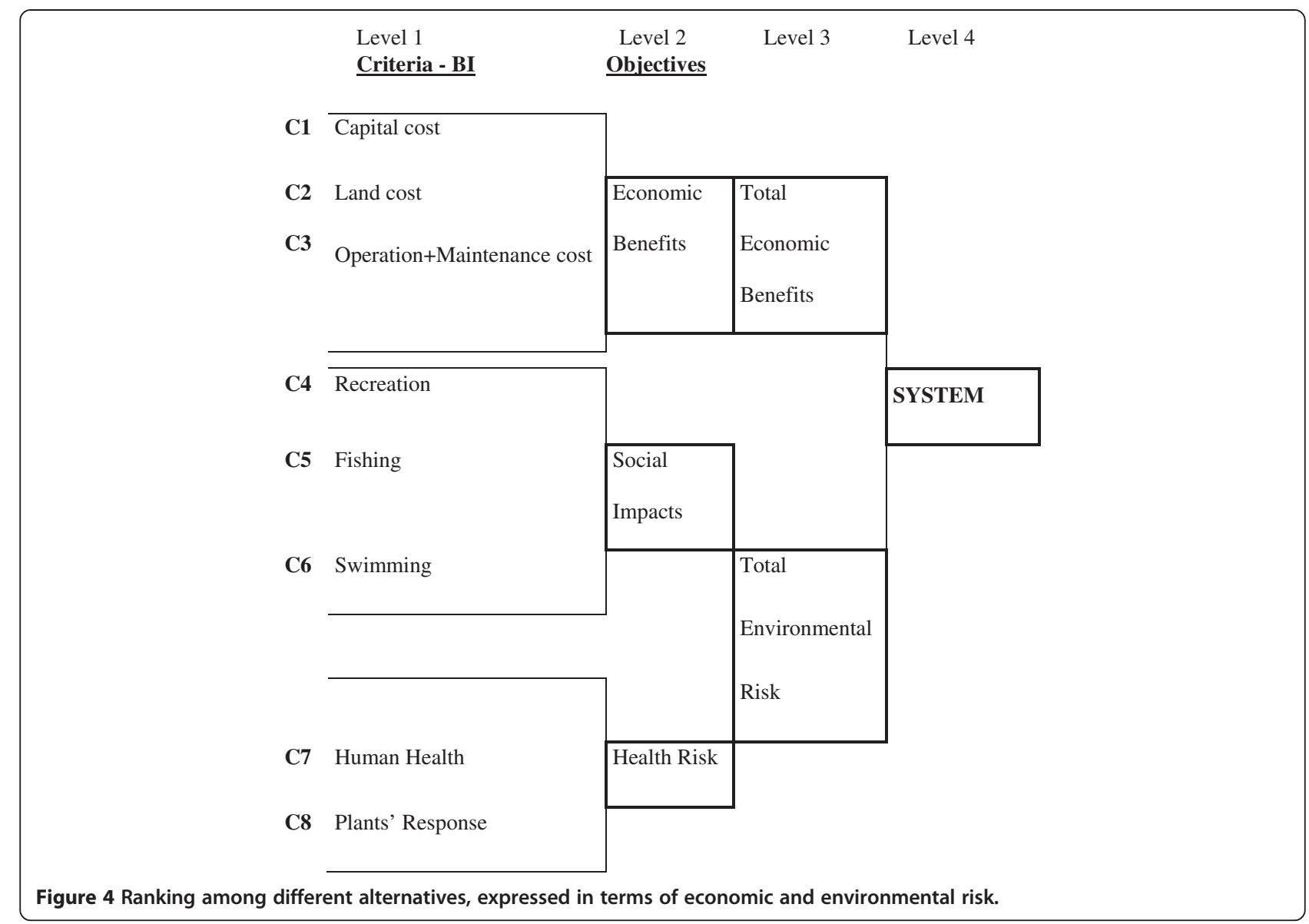

indicators are different and thus it is difficult to make direct comparisons; their values should be normalised onto the 0 to 1 interval.

Representing the A, B, C, D, and E normalised values with $S_{i}$ and the different weights assigned to each criterion by $\mathrm{w}_{\mathrm{i}}$, the following relationship (Equation 3) gives the general rule by which we move up from a specific level to a more general level:

$$
L_{i}=\left(\sum_{i=1}^{n} w_{i}\left(S_{i}\right)^{p}\right)^{1 / p}
$$

where $L_{i}$ represents the normalised values for every more general group and $p$ is the balancing factor among indicators for a group. The balancing factor reflects the importance of the maximal deviation of the indicators, where the maximal deviation means the maximum difference between an indicated value and the best value for the indicator (Dahab and Lee 1991).

The final composite indicator is obtained by applying the above rule to the two general indicators, the Total Environmental Risk and the Total Economic Benefit. The result is a vector. Ranking among alternatives is based on the minimum composite distance, as explained later.

This is a simple example that shows the perception of such a problem and which may be resolved with the help of a multi criteria decision making (MCDM) program. In this case, many other factors will be included, such as risk and reliability, fuzzy set theory and uncertainty. Some of the techniques used to apply MCDM are ELECTRE (Elimination Et Choix Traduissant la Realite) (ELECTRE) (Nachtnebel 1994) and the one mentioned above, the technique of Minimum Distance from the Ideal Point.

There are two different distance-based techniques, goal programming and composite programming. The first allows the decision maker (DM) to obtain results by defining a preferred solution as the one that minimises the sum of the deviations from the prescribed set of target values. The second first normalises the objectives and then identifies solutions which are closest to the ideal point as determined by some measure of distance.

The ELECTRE method is used when the outcomes of alternatives cannot be quantitatively assessed and whilst with the use of the distance-based technique the DM 


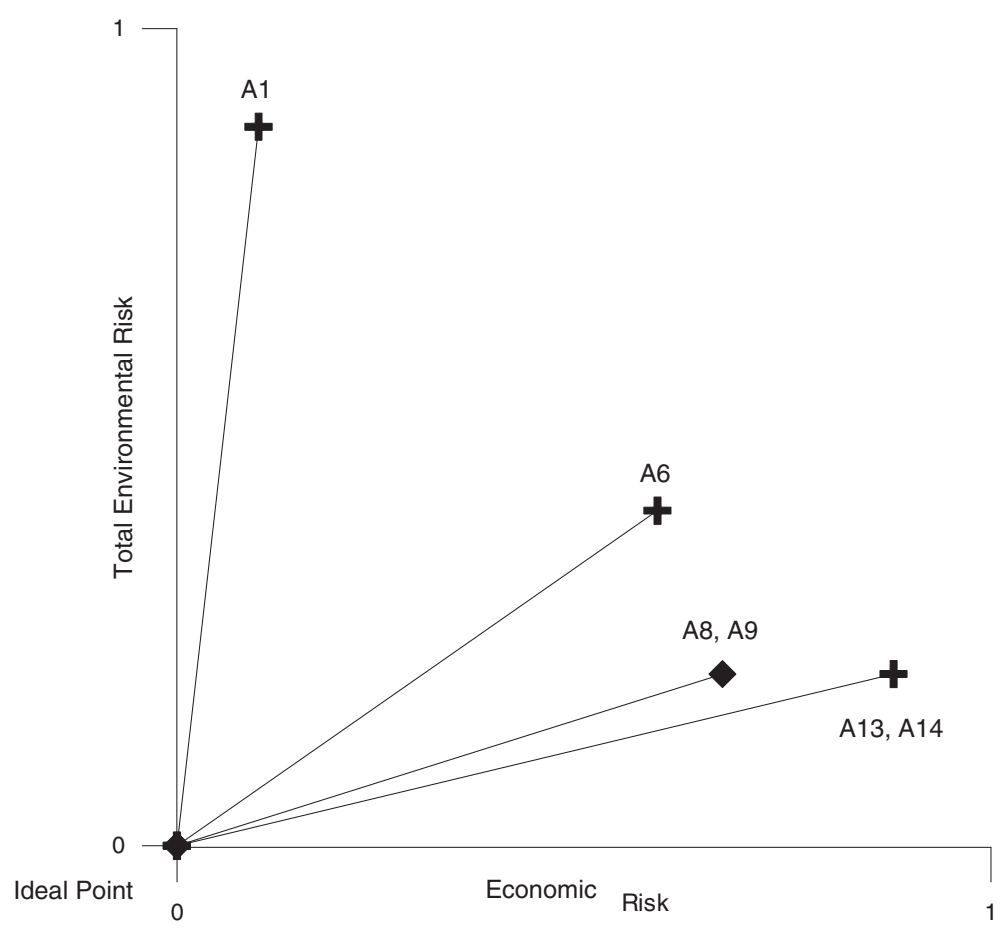

Figure 5 Composite structure of criteria.

may see that one alternative is better than the other, he cannot quantify how much better. The ELECTRE technique is applied as I, II and III, according to the information about the preference structure.

\section{The compromise solution}

One of the more promising methods is that of composite programming. Having arrived at some composite economic benefit and total environmental risk indicators, we should choose one solution. An example of ranking between different strategies-solutions based on the minimum composite distance from the ideal point follows. In this case the ideal point is 0 (zero risk), as we are looking for the lowest environmental risk and the least economic impact. The final system indicators can be formed by composing environmental and economic risk. Developing a composite programming software is a tool for ranking alternatives and determining the 'best' compromise solution from all the alternative solutions.

In the following Figure 4, we give an example of calculating the minimum distance from the ideal point, on an $x$ - and $y$-axis system, where $\mathrm{x}$ values stand for'economic risk indicator, values and $y$ for 'environmental risk indicator' values. We may see that after this example we arrive at the point where, beyond a certain level of wastewater treatment, the two different irrigation solutions of food crop and no-food crop could be treated as one (A8, A9) and (A13, A14). Ranking of alternative solutions results as follows:

1. Secondary treatment + chlorination - food crop, no food crop irrigation (A8, A9)

2. Secondary treatment + chlorination - Axios River (A6)

3. Tertiary treatment - food crop, no food crop irrigation (A13, A14)

4. No treatment - open sea (A1)

\section{Conclusions}

Risk analysis is an integrated framework for wastewater reclamation and reuse consisting of risk assessment (physical system, loads, uncertainties, risk quantification), and risk management (alternative risks, costs, social and health aspects). The main advantage of this approach is the combination with a MCDA methodology, in order to take into account different criteria of wastewater reuse. The final goal is the development of a Decision Support System (DSS), leading to a compromise solution, which is defined not as an optimum but as a'non-inferior'solution, which is the one for which all objective functions are improved. 
For the design of wastewater reuse and the control of the associated risks, data of maximum pollutant concentrations play a major role. These values should be taken into consideration when various alternatives of wastewater reclamation and reuse are studied. In this paper it is shown how risk analysis may be used in order to quantify the risk of wastewater reuse. The methodology should lead to a decision support system to be applied by local authorities responsible for wastewater treatment and disposal.

\section{Competing interests}

The authors declare that they have no competing interests.

\section{Authors' contributions}

All authors read and approved the final manuscript.

Received: 5 April 2012 Accepted: 1 August 2012

Published: 1 August 2012

\section{References}

Angelakis AN (1993) The necessity of reclamation and reuse of municipal wastewater effluent in the Mediterranean region. In: (ed) HELECO'93, vol. 1st edn. Technical Chamber of Greece, Athens, Greece, pp 315-330, in Greek Ganoulis J (2003) Evaluating alternative strategies of wastewater recycling and reuse in the Mediterranean area. Water Science Technology: Water Supply 3 (4):11-19

Ganoulis J (2009) Risk Analysis of Water Pollution. WILEY-VCH, Weinheim

Nachtnebel HP (1994) Multicriterion Decision Making Methods with Ordinal and Cardinal Scales. In: Bogardi J, Nachtnebel HP (eds) ELECTRE I-III. Multicriterion Decision Analysis in Water Resources Management, UNESCO, Paris, pp 113-150

Dahab MF, Lee YW (1991) Risk management for nitrate-contaminated groundwater under imprecise conditions. In: (ed) NATO ASI on Risk and Reliability in Water Resources and Environmental Engineering. Porto Karras, Greece, 18-28 May 1991

Papadopoulos I (1989) Reuse of treated effluent for irrigation in Cyprus. CEFIGRE, CEF-206/ST04

Pettygrove GS, Asano T (eds) (1985) Irrigation with reclaimed municipal wastewater: a guidance manual. Lewis Publishers, London

Saied M, Koundi A (1990) Reutilisation des eaux épurées en Tunisie. 2nd Int. Symp. on Sea Protection, Marseille

Sne M (1990) Transfer of Technology: the Israeli Experience. Role and Function of Extension in Irrigation. Report to the Ministry of Agriculture

WHO (2011) Waste stabilisation ponds: design manual for Mediterranean Europe. Geneva

doi:10.1186/2251-7715-1-3

Cite this article as: Ganoulis: Risk analysis of wastewater reuse in agriculture. International Journal Of Recycling of Organic Waste in Agriculture 2012 1:3.

\section{Submit your manuscript to a SpringerOpen ${ }^{\circ}$ journal and benefit from:}

- Convenient online submission

Rigorous peer review

- Immediate publication on acceptance

- Open access: articles freely available online

- High visibility within the field

- Retaining the copyright to your article 